ARTICLE

Received 28 Jul 2015 | Accepted 6 May 2016 | Published 10 Jun 2016

\title{
Efficient hydrogen evolution in transition metal dichalcogenides via a simple one-step hydrazine reaction
}

Dustin R. Cummins ${ }^{1,2}$, Ulises Martinez ${ }^{1}$, Andriy Sherehiy², Rajesh Kappera ${ }^{1,3}$, Alejandro Martinez-Garcia², Roland K. Schulze ${ }^{4}$, Jacek Jasinski ${ }^{2}$, Jing Zhang ${ }^{5}$, Ram K. Gupta ${ }^{6}$, Jun Lou ${ }^{5}$, Manish Chhowalla ${ }^{3}$, Gamini Sumanasekera², Aditya D. Mohite ${ }^{1}$, Mahendra K. Sunkara² \& Gautam Gupta ${ }^{1}$

Hydrogen evolution reaction is catalysed efficiently with precious metals, such as platinum; however, transition metal dichalcogenides have recently emerged as a promising class of materials for electrocatalysis, but these materials still have low activity and durability when compared with precious metals. Here we report a simple one-step scalable approach, where $\mathrm{MoO}_{x} / \mathrm{MoS}_{2}$ core-shell nanowires and molybdenum disulfide sheets are exposed to dilute aqueous hydrazine at room temperature, which results in marked improvement in electrocatalytic performance. The nanowires exhibit $\sim 100 \mathrm{mV}$ improvement in overpotential following exposure to dilute hydrazine, while also showing a 10-fold increase in current density and a significant change in Tafel slope. In situ electrical, gate-dependent measurements and spectroscopic investigations reveal that hydrazine acts as an electron dopant in molybdenum disulfide, increasing its conductivity, while also reducing the $\mathrm{MoO}_{\mathrm{x}}$ core in the core-shell nanowires, which leads to improved electrocatalytic performance.

\footnotetext{
${ }^{1}$ Materials Physics and Applications (MPA-11), Los Alamos National Laboratory, Los Alamos, New Mexico 87545, USA. ${ }^{2}$ Chemical Engineering and Conn Center for Renewable Energy Research, University of Louisville, Louisville, Kentucky 40292, USA. ${ }^{3}$ Materials Science and Engineering, Rutgers University, Piscataway, New Jersey 08854, USA. ${ }^{4}$ Materials Science and Technology (MST-6), Los Alamos National Laboratory, Los Alamos, New Mexico 87545, USA. ${ }^{5}$ Materials Science and NanoEngineering, Rice University, Houston, Texas 77005, USA. ${ }^{6}$ Chemistry, Pittsburg State University, Pittsburg, Kansas 66762 , USA. Correspondence and requests for materials should be addressed to M.K.S. (email: mahendra@louisville.edu) or to G.G. (email: gautam@lanl.gov).
} 
$\mathrm{H}$ ydrogen has the potential to be a zero-emission, renewable fuel; however, today it is primarily obtained from thermal steam reforming of natural gas ${ }^{1-4}$. It can be produced via water splitting, but the high cost of precious metal catalysts and rare earth materials that are currently used present a challenge to large scale implementation ${ }^{5-8}$. Recently, layered transition metal dichalcogenides (TMDs), such as $\mathrm{WS}_{2}, \mathrm{MoS}_{2}$ and so on, have been explored as a viable alternative to precious metal catalysts ${ }^{9,10}$. Bulk $\mathrm{MoS}_{2}$ powders have limited catalytic activity due to an inert crystal basal plane and low in-plane conductivity ${ }^{11}$. High electrocatalytic activity can be achieved by either increasing the exposure of the active edge planes ${ }^{12-17}$, increasing the conductivity of $\mathrm{MoS}_{2}$ (refs 18-20), phase transformation $^{21-26}$, use of a co-catalyst ${ }^{27}$ or a combination of these approaches ${ }^{28-30}$. Of these techniques, phase transformation from semiconducting (bulk hexagonal $2 \mathrm{H}-\mathrm{MoS}_{2}$ ) to a metastable trigonal crystal structure $\left(1 \mathrm{~T}-\mathrm{MoS}_{2}\right)$, which has metallic properties and does not suffer from anisotropy, has recently shown the most promise for electrochemical and opto-electronic applications ${ }^{28,31-33}$. Phase-transformed TMDs, obtained via

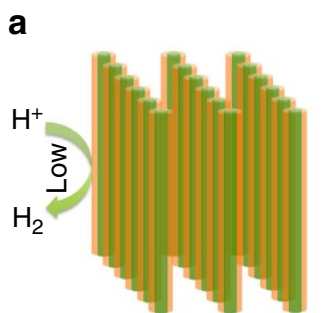

$\mathrm{MoO}_{\mathrm{x}}$ core $/ \mathrm{MoS}_{2}$ shell
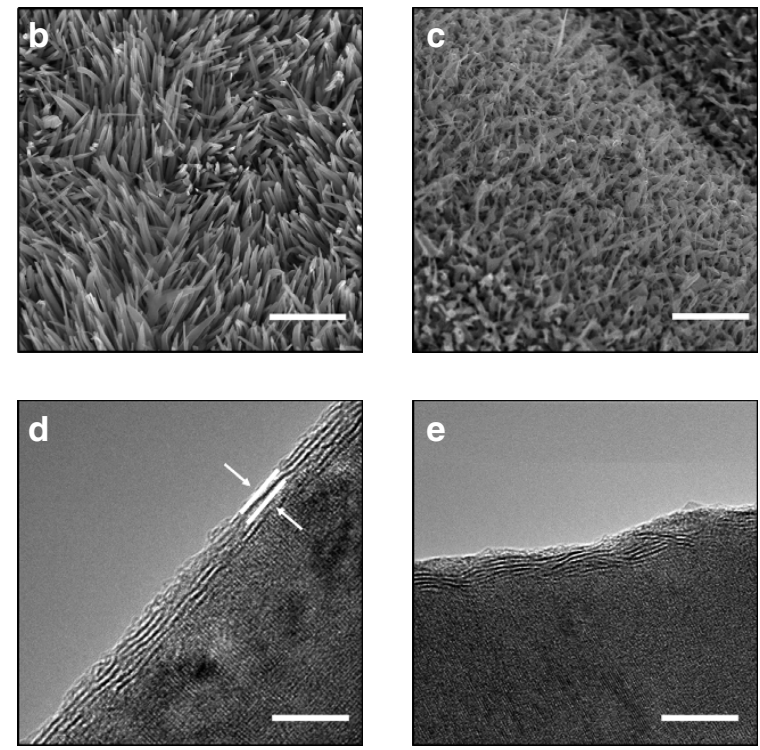

Figure 1 | Schematic representation of hydrazine treatment and microscopic analysis of $\mathbf{M o O}_{\mathbf{x}} / \mathbf{M o S}_{\mathbf{2}}$ core-shell nanowires. (a) Schematic representation of exposure of $\mathrm{MoO}_{x} / \mathrm{MoS}_{2}$ core-shell nanowire array to dilute hydrazine under ambient conditions. (b) SEM image of as-grown $\mathrm{MoO}_{x} / \mathrm{MoS}_{2}$ core-shell nanowire array. Scale bar, $2 \mu \mathrm{m}$. (c) SEM imaging $\mathrm{MoO}_{x} / \mathrm{MoS}_{2}$ core-shell nanowires following dilute hydrazine treatment, showing that the overall nanowire morphology is maintained. Scale bar, $2 \mu \mathrm{m}$. (d) High-resolution TEM (HRTEM) of as-grown nanowire, showing thin ( 3-5 nm) $\mathrm{MoS}_{2}$ shell on a single crystal $\mathrm{MoO}_{x}$ core. The $\mathrm{MoS}_{2}$ has the typical interlayer spacing of $6.2 \AA$, denoted in image by two parallel lines. Scale bar, $5 \mathrm{~nm}$. (e) HRTEM of the $\mathrm{MoO}_{x} / \mathrm{MoS}_{2}$ core-shell nanowire after exposure to hydrazine. Scale bar, $5 \mathrm{~nm}$. lithium intercalation, result in very efficient hydrogen evolution reaction (HER) catalytic characteristics; however, the processing conditions are expensive, time consuming (days), involve use of inert glove box atmosphere and often require elevated temperatures $\left(100^{\circ} \mathrm{C}\right)$. Lithium processing has also been shown to result in the formation of $\mathrm{Li}_{2} \mathrm{~S}$ nanoparticle contaminants 9 . High-aspect ratio structures, such as one-dimensional core-shell nanowires $^{29}$, also have the potential to achieve high HER activity. Although these structures possess properties such as high surface area and a conductive reduced oxide core, the primary drawback is that synthesis methods lead to the relatively inert basal plane of the $\mathrm{MoS}_{2}$ shell growing parallel to the length of the nanowire. This reduces the exposure of available active edge sites, resulting in lower catalytic activity for HER than theoretically achievable.

Hydrazine has been well researched as a reducing agent in twodimensional (2D) reduced graphene oxide ${ }^{34}$ and demonstrated as an $n$-type dopant in graphene $e^{35,36}$, single-walled carbon nanotubes, both semiconducting and metallic ${ }^{37,38}$, as well as observed in inorganic nanocrystalline systems ${ }^{39,40}$, but its effects on layered TMDs and electrocatalytic properties have not been previously investigated to date. Chemical modification of the $\mathrm{MoS}_{2}$ inert basal plane to increase its charge carrier concentration, that is, electron doping, could lead to marked improvement in electrocatalytic activity.

Here we report a simple process, in which exposure of the $\mathrm{MoO}_{\mathrm{x}} / \mathrm{MoS}_{2}$ core-shell nanowire arrays, as well as pure $\mathrm{MoS}_{2}$ particles and $2 \mathrm{D}$ sheets, to dilute hydrazine $\left(\mathrm{N}_{2} \mathrm{H}_{4}\right)$ results in a marked improvement in catalytic activity towards HER, that is, both a significant improvement in overpotential $(\sim 100 \mathrm{mV}$ versus the reversible hydrogen electrode (RHE)), which is among the lowest reported HER overpotentials for any $\mathrm{MoS}_{2}$ architecture, and a 10-fold increase in current density $(\sim 2$ to $22 \mathrm{~mA} \mathrm{~cm}^{-2}$ ). Detailed characterization and conductivity measurements of $\mathrm{MoO}_{\mathrm{x}} / \mathrm{MoS}_{2}$ core-shell nanowires, as well as pure $\mathrm{MoS}_{2}$ particles and sheets, show that hydrazine is acting as an electron dopant, donating electrons to increase the conductivity of $\mathrm{MoS}_{2}$, which leads to improved electrocatalytic activity. In the case of the core-shell nanowires, hydrazine further reduces the oxide core, which enhances conductivity and facilitates the charge transfer kinetics in the system, synergistically improving the HER performance of core-shell nanowires after exposure to hydrazine. This 'activation' of the normally inert TMD basal plane by electron doping from hydrazine presents a unique opportunity to serves as a novel direction for efficient catalytic development and the use of simple processing techniques that can rival state-of-art platinum catalysts.

\section{Results}

Synthesis and characterization of $\mathrm{MoO}_{\mathrm{x}} / \mathrm{MoS}_{2}$ architectures. Figure 1a shows a schematic representation of a simple hydrazine treatment; the as-grown $\mathrm{MoO}_{\mathrm{x}} / \mathrm{MoS}_{2}$ core-shell nanowires are exposed to a dilute hydrazine ( $1 \%$ in water) at room temperature for $10 \mathrm{~min}$. Figure $1 \mathrm{~b}$ shows the scanning electron microscopic (SEM) image of an as-grown, vertically oriented $\mathrm{MoO}_{\mathrm{x}} / \mathrm{MoS}_{2}$ core-shell nanowire array on $\mathrm{SiO}_{2}$ substrates. Nanowires are typically $1-2 \mu \mathrm{m}$ in length, with diameters of $20-50 \mathrm{~nm}$. A thin $(2-5 \mathrm{~nm})$ highly oriented crystalline $\mathrm{MoS}_{2}$ shell is grown epitaxially on a single-crystal reduced $\mathrm{MoO}_{\mathrm{x}}$ core, as can be seen using high-resolution transmission electron microscopy (Fig. 1d). $\mathrm{MoO}_{3}$ nanowire arrays are deposited on $\mathrm{SiO}_{2}$ substrates using chemical vapor deposition (CVD), followed by the sulfurization reaction at $300{ }^{\circ} \mathrm{C}$ under low pressures of $99 \% \mathrm{H}_{2} \mathrm{~S}$ (100 mTorr) for $2 \mathrm{~h}$, leading to a thin $(2-5 \mathrm{~nm})$ single crystalline $\mathrm{MoS}_{2}$ on a single crystal $\mathrm{MoO}_{\mathrm{x}}$ core. The synthesis methods of the $\mathrm{MoO}_{\mathrm{x}} / \mathrm{MoS}_{2}$ core-shell nanowires are described in more detail 
elsewhere ${ }^{29,30,41}$. After exposure to hydrazine, SEM (Fig. 1c) shows minimal disruption of the nanowire morphology and there is no evidence of crystallographic disruption of the $\mathrm{MoS}_{2}$ shell, as shown in Fig. 1e.

Electrochemical performance of materials. The nanowires are dispersed in distilled water, removing any agglomerated hydrazine on the surface and transferred $\left(\sim 70 \mu \mathrm{g} \mathrm{cm}^{-2}\right)$ to a glassy carbon electrode for electrochemical characterization. Figure 2a shows a linear sweep voltammogram of the as-grown and hydrazine-treated nanowires. All of these electrocatalytic measurements are corrected for ohmic potential (iR) losses in the system $(\sim 12 \mathrm{ohms})$; this resistance calculation is shown in Supplementary Fig. 1. The measured HER onset potential for the as-grown nanowires is approximately $-200 \mathrm{mV}$ versus RHE and a current density of $\sim 2 \mathrm{~mA} \mathrm{~cm}^{-2}$ at $-0.35 \mathrm{~V}$ versus RHE is obtained. After exposure to $1 \%$ hydrazine, the onset potential improves to approximately $-100 \mathrm{mV}$ versus RHE and the current density increases to $\sim 22 \mathrm{~mA} \mathrm{~cm}^{-2}$ at $-0.35 \mathrm{~V}$. Hydrazine treatment on multiple nanowire samples indicate that this electrochemical performance is highly reproducible (Supplementary Fig. 2). a

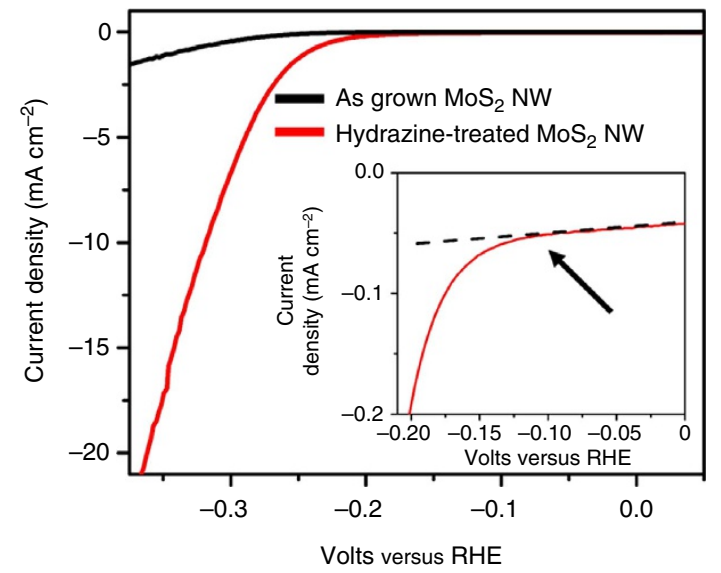

C

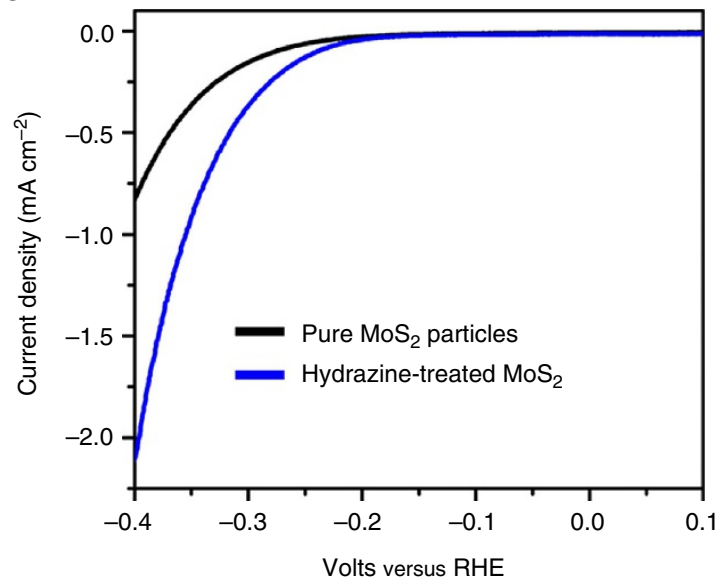

b

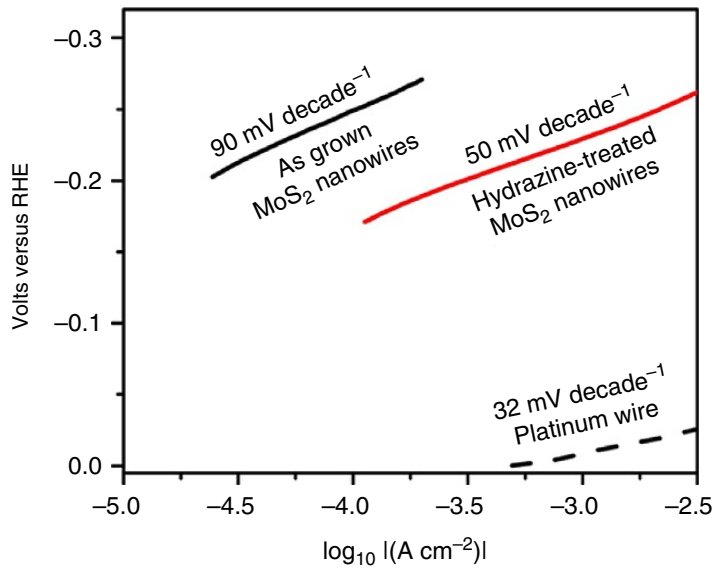

d

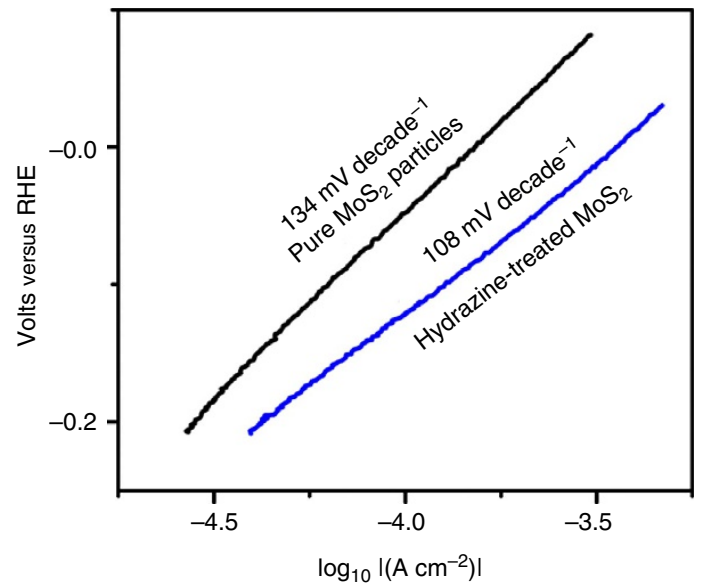

e

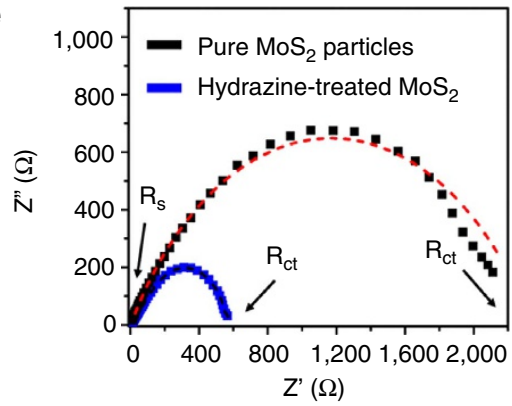

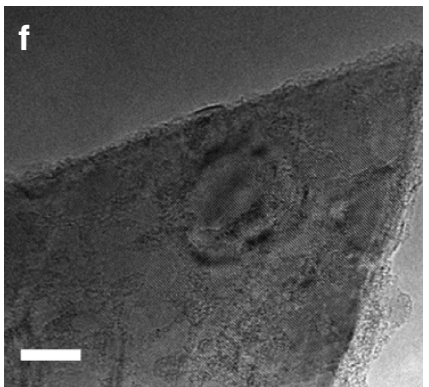

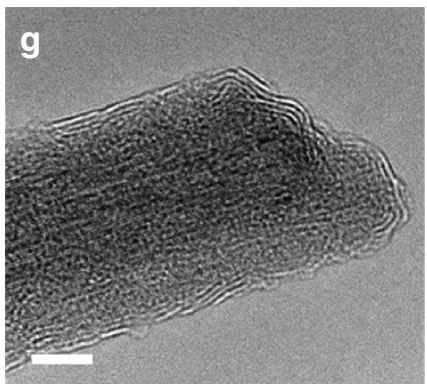

Figure 2 | Electrochemical analysis of $\mathbf{M o O}_{\mathbf{x}} / \mathbf{M o S}_{\mathbf{2}}$ core-shell nanowires and $\mathbf{M o S}_{\mathbf{2}}$ particles. (a) Linear sweep voltammetry for as-grown $\mathrm{MoO}_{x} / \mathrm{MoS}_{2}$ core-shell nanowire (black curve) and after exposure to $1 \%$ Hydrazine (red curve). (b) Tafel slopes for as-grown $\mathrm{MoO}_{x} / \mathrm{MoS}_{2}$ core-shell nanowires (black curve), 1\% hydrazine-treated nanowires (red curve), and a platinum wire (dotted black curve). (c) Linear voltammograms and corresponding (d) Tafel slope analysis of $\mathrm{MoS}_{2}$ particles before (black curve) and following exposure to dilute hydrazine (blue curve). (e) Electrochemical impedance spectroscopy (EIS) Nyquist plots of the $\mathrm{MoS}_{2}$ particles following exposure to hydrazine, with line fits shown by dotted lines. (f) High-resolution TEM (HRTEM) of $2 \mathrm{H}-\mathrm{MoS}_{2}$ particle. Scale bar, $5 \mathrm{~nm}$. (g) HRTEM of as-grown MoO $\mathrm{MoS}_{2}$ core-shell nanowire. Scale bar, $10 \mathrm{~nm}$. 
The rate of hydrogen evolution is limited by either proton adsorption onto an active site or evolution of the formed hydrogen from the surface. A high Tafel slope $(120 \mathrm{mV}$ per decade) is indicative of proton adsorption (Volmer step) as the rate-limiting step, while a lower Tafel slope $(30$ or $40 \mathrm{mV}$ per decade) indicates that the evolution of molecular hydrogen from the catalyst is rate limiting (Heyrovsky or Tafel step, respectively $)^{7,42,43}$. Figure $2 \mathrm{~b}$ shows the Tafel plots for these voltammograms. The as-grown $\mathrm{MoO}_{\mathrm{x}} / \mathrm{MoS}_{2}$ core-shell nanowires show a Tafel slope of $90 \mathrm{mV}$ per decade, suggesting that adsorption of protons from the electrolyte is the rate-limiting step. Since the relatively inactive basal plane of the $2 \mathrm{H}-\mathrm{MoS}_{2}$ shell is grown parallel to the $\mathrm{MoO}_{\mathrm{x}}$ core nanowire, there are fewer catalytically active sites available for proton adsorption. After exposure to $1 \%$ hydrazine, the Tafel slope decreases to $50 \mathrm{mV}$ per decade, indicating that the evolution of hydrogen via the combination of two adsorbed protons becomes the rate-limiting step. These results show that the hydrazine treatment significantly facilitates the adsorption of protons onto the catalyst surface. For comparison, the Tafel slope of a platinum wire is shown in Fig. $2 b$ (dashed black curve); platinum has a Tafel slope of $\sim 30 \mathrm{mV}$ per decade, which indicates proton adsorption is favourable and hydrogen evolution is the rate-limiting step ${ }^{42,43}$.

To corroborate the effects of hydrazine on TMDs without a core-shell nanowire architecture, pure $\mathrm{MoS}_{2}$ particles are exposed to dilute hydrazine. Figure $2 \mathrm{c}$ shows the linear voltammetry plots of bulk $\mathrm{MoS}_{2}$ powder with and without hydrazine. Bulk powder shows poor catalytic activity for the HER; following the hydrazine treatment, an improvement in both the current density and HER overpotential is observed. Tafel analysis (Fig. 2d) shows a decrease in the Tafel slope of the pure $2 \mathrm{H}-\mathrm{MoS}_{2}$ particles, indicative of increased favourability for proton absorption onto the catalysis surface. Furthermore, electrochemical impedance spectroscopy of the $\mathrm{MoS}_{2}$ particles before and after hydrazine treatment (Fig. 2e) show a significant decrease in the charge transfer resistance. $A R_{s}-\left(C P E-R_{c t}\right)$ circuit diagram is used to fit the experimental electrochemical impedance spectroscopy data. The solution resistance $\left(R_{\mathrm{s}}\right)$ remains nearly constant $(\sim 12 \Omega)$, whereas the charge transfer resistance $\left(R_{\mathrm{ct}}\right)$ decreases from $\sim 2,340$ to $\sim 625 \Omega$, indicative of enhanced conductivity after the hydrazine treatment.

To quantify the improvement in catalytic activity following the hydrazine treatment, turnover frequency (TOF) is calculated for the $\mathrm{MoO}_{\mathrm{x}} / \mathrm{MoS}_{2}$ core-shell nanowires and $\mathrm{MoS}_{2}$ particles using the following equation:

$$
\operatorname{TOF}\left(s^{-1}\right)=\frac{i_{0}\left(\frac{A}{\mathrm{~cm}^{2}}\right)}{\# \frac{\text { sites }}{\mathrm{cm}^{2}} * 1.602 \times 10^{-19}\left(\frac{C}{e^{-}}\right) * 2\left(\frac{e^{-}}{H_{2}}\right)}
$$

Exchange current densities $\left(i_{0}\right)$ are calculated from the Tafel equation, while the number of active sites is calculated from cyclic voltammograms of $\mathrm{MoS}_{2}$ particles and $\mathrm{MoO}_{\mathrm{x}} / \mathrm{MoS}_{2}$ core-shell nanowires, both as-grown and treated with hydrazine. Following
HER measurements, the potential applied to the working electrode was driven to high oxidation potentials $(\sim 1.4 \mathrm{~V}$ versus RHE) to convert $\mathrm{MoS}_{2}$ particles to $\mathrm{MoO}_{3}$ (ref. 44). Calculation of active sites was obtained from the reduction charge transfer $\left(\mathrm{MoO}_{3} \rightarrow \mathrm{Mo}^{0}\right)$ occurring at $\sim-0.3$ to $0.0 \mathrm{~V}$ (ref. 29), assuming that each $\mathrm{Mo}^{3}+$ reduced to $\mathrm{Mo}^{0}$ corresponded to one $\mathrm{MoS}_{2}$ site. The results of these electrochemical decompositions to calculate surface area are shown in Supplementary Figs 3 and 4 . The number of active sites for $\mathrm{MoS}_{2}$ bulk particles are similar before and after hydrazine treatment, $9.0 \times 10^{14}$ and $9.8 \times 10^{14}$ $\mathrm{MoS}_{2}$ sites per $\mathrm{cm}^{2}$, while Tafel analysis indicates an increase in exchange current density from $8.4 \times 10^{-6}$ to $1.7 \times 10^{-5}$ $\mathrm{A} \mathrm{cm}^{-2}$. Using these values, the calculated TOF values increase for the $\mathrm{MoS}_{2}$ particles following the hydrazine treatment, from $0.03-0.05 \mathrm{~s}^{-1}$, while the number of active sites remain relatively unchanged. Summary of these obtained values, shown in Table 1, are consistent with reports by other researchers $31,45,46$.

A similar analysis process is performed to calculate TOF values for the $\mathrm{MoO}_{\mathrm{x}} / \mathrm{MoS}_{2}$ core-shell nanowires. The -0.3 to $0.0 \mathrm{~V}$ region used in the particle calculations is more convoluted in the nanowires' case with the combination of core and shell oxidation-reduction peaks (Supplementary Fig. 4). Thus, the oxidation of $\mathrm{MoS}_{2}$ to $\mathrm{MoO}_{3}$ involving $11 \mathrm{e}^{-}$was used as the region for determining the number of $\mathrm{MoS}_{2}$ sites (as explained by Chen et al. $)^{29}$. Interestingly, the series of oxidation-reduction decomposition peaks observed in the as-grown nanowires, resulting from the $\mathrm{MoO}_{\mathrm{x}}$ core, are not observed following hydrazine treatment. This suggests that the hydrazine, in addition to doping of $\mathrm{MoS}_{2}$ shell, also reduces the oxide core, which increases its conductivity. The calculated number of $\mathrm{MoS}_{2}$ sites per surface area for the as-grown $\mathrm{MoO}_{\mathrm{x}} / \mathrm{MoS}_{2}$ core-shell nanowires is $\sim 5.9 \times 10^{14}$ sites per $\mathrm{cm}^{2}$. There is almost no change in the concentration of active sites in the nanowires following exposure to hydrazine, $6.0 \times 10^{14}$ sites per $\mathrm{cm}^{2}$; this is confirmed by no observed physical change from SEM and TEM analysis (Fig. 1). Exchange current densities calculated from the obtained Tafel equations are $7.5 \times 10^{-6}$ and $4.5 \times 10^{-5} \mathrm{~A} \mathrm{~cm}^{-2}$ for the as-grown and hydrazine-treated $\mathrm{MoO}_{\mathrm{x}} / \mathrm{MoS}_{2}$ core-shell nanowires, respectively. This results in an increase of TOF from 0.04 to $0.2 \mathrm{~s}^{-1}$. This fivefold improvement in TOF quantitatively shows the effect of hydrazine treatment on the electrocatalytic properties of $\mathrm{MoS}_{2}$ shelled nanowires.

Although, there is clear improvement in HER performance characteristics, the magnitude of the change in the bulk $\mathrm{MoS}_{2}$ is lower when compared with nanowires. This can be attributed to the difference in structure; the $\mathrm{MoS}_{2}$ powder particles are composed of several tens of molecular $\mathrm{MoS}_{2}$ layers with random orientations, as seen in Fig. 2f. This is in contrast to the core-shell nanowires, which have a few molecular layer thick $\mathrm{MoS}_{2}$ shell on an oxide core, as shown in Fig. 2g.

Hydrazine is a reducing agent, as well as an electron dopant; we hypothesize that it interacts with the oxide core, further reducing it and increasing the intra-particle conductivity of the nanowire,

Table 1 | Electrochemical parameters with hydrazine treatment of $\mathrm{MoS}_{2}$.

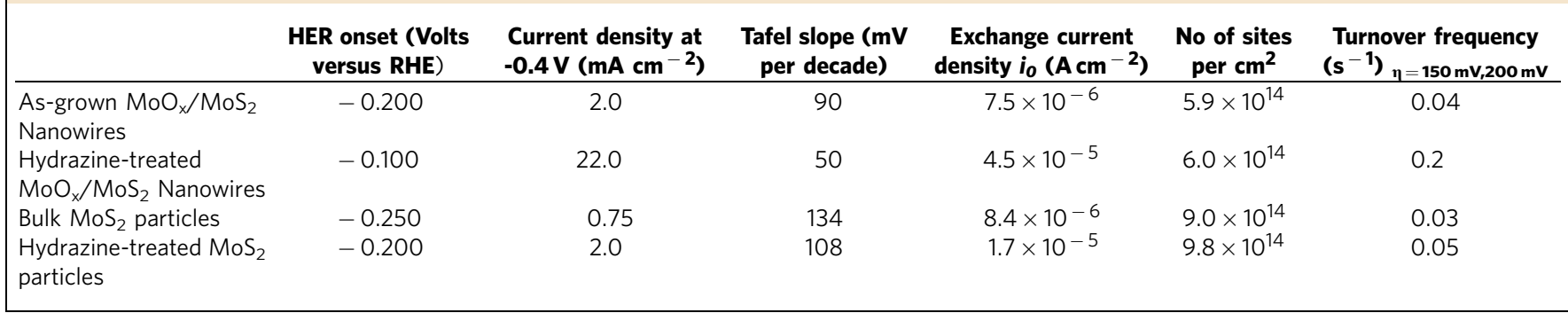


while hydrazine also electron dopes the $\mathrm{MoS}_{2}$ surface. To test the hypothesis of reduction of oxide core, pure $\mathrm{MoO}_{3}$ nanowires are treated with dilute $1 \%$ hydrazine, reported in the Supplementary Fig. 5. Pure $\mathrm{MoO}_{3}$ is catalytically inactive and decomposes quickly in acid solutions ${ }^{47}$ As expected, the $\mathrm{MoO}_{3}$ nanowires show no catalytic activity and decompose in the $0.5 \mathrm{M} \mathrm{H}_{2} \mathrm{SO}_{4}$. When exposed to hydrazine before testing, the $\mathrm{MoO}_{3}$ reduction and oxidation peaks are no longer observed, suggesting that the oxide has been reduced. This experiment supports a synergistic mechanism; hydrazine improves electron conductivity of the nanowire core, that is, intra-particle conductivity, while also electron doping the $\mathrm{MoS}_{2}$ surface (shown in pure $\mathrm{MoS}_{2}$ powder). The $\mathrm{MoO}_{\mathrm{x}} / \mathrm{MoS}_{2}$ core-shell nanowire morphology, combined with the hydrazine treatment, uniquely provides architecture for an optimized electrocatalyst. The reduction of the $\mathrm{MoO}_{\mathrm{x}}$ core by hydrazine is also confirmed by X-ray photoelectron spectroscopy (XPS) of a $\mathrm{MoO}_{\mathrm{x}} / \mathrm{MoS}_{2}$ core-shell nanowire array in Fig. 3.

Spectroscopic investigation of $\mathrm{MoO}_{\mathrm{x}} / \mathrm{MoS}_{2}$ architectures. The core level binding energies of molybdenum and sulfur in as-grown $\mathrm{MoO}_{\mathrm{x}} / \mathrm{MoS}_{2}$ core-shell nanowires are analysed using XPS, depicted in Fig. 3. The as-grown $\mathrm{MoO}_{\mathrm{x}} / \mathrm{MoS}_{2}$ core-shell nanowires show strong doublet peaks at $229 \mathrm{eV}$, which are consistent with literature values for $\mathrm{Mo}^{4+} 3 \mathrm{~d}_{5 / 2}$ and $\mathrm{Mo}^{4+} 3 \mathrm{~d}_{3 / 2}$ of $2 \mathrm{H}-\mathrm{MoS}_{2}$, shown by the red curves ${ }^{21}$. The $\mathrm{MoO}_{\mathrm{x}}$ core results in a convolution of two oxidation states for $\mathrm{Mo}^{6+}$ in the reduced oxide core, shown by the dark and light blue signals at $\sim 232.6$ and $230.6 \mathrm{eV}$; these binding energies suggest $\mathrm{MoO}_{3}$ and reduced $\mathrm{MoO}_{3-x}$. This is a result of incomplete reaction between the original $\mathrm{MoO}_{3}$ nanowires and the $\mathrm{H}_{2} \mathrm{~S}$ during synthesis ${ }^{29}$. Following exposure to hydrazine, the partially reduced oxide core continues to reduce, indicated by the shift in Mo $3 \mathrm{~d}$ signal towards lower binding energies of the further reduced oxide core $\left(\mathrm{MoO}_{\mathrm{x}}\right), \sim 230.6$ and $229.6 \mathrm{eV}$, respectively. It is established that reduced molybdenum oxide has almost metallic conductivity ${ }^{48}$; hydrazine, as a reducing agent, is increasing the intra-particle conductivity of the nanowire core. Despite the shift in Mo corresponding to the molybdenum oxide core, there is no shift in the $\mathrm{MoS}_{2}$ Mo 3d binding energies. When observing the $S$ 2p signal for the $\mathrm{MoS}_{2}$ nanowire shell, the as-grown sample shows the clear doublet signal at $\sim 162 \mathrm{eV}$, typical for $2 \mathrm{H}-\mathrm{MoS}_{2}$. After

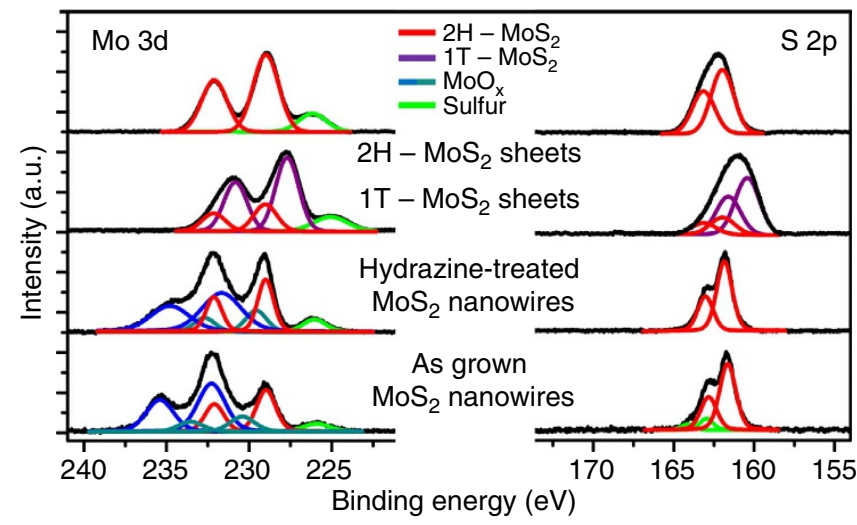

Figure 3 | XPS Spectroscopy following hydrazine treatment. Spectra for $\mathrm{MoO}_{x} / \mathrm{MoS}_{2}$ core-shell nanowire array before and after hydrazine treatment, showing the Mo $3 \mathrm{~d}, \mathrm{~S} 2 \mathrm{~s}$, and $\mathrm{S} 2 \mathrm{p}$ core level binding energies. The red curves denote the Mo $3 \mathrm{~d}$ and $\mathrm{S} 2 \mathrm{p}$ signals corresponding to $2 \mathrm{H}$ $\mathrm{MoS}_{2}$, with the purple curves showing the shift resulting from the phase transformation to $1 \mathrm{~T}-\mathrm{MoS}_{2}$. The $\mathrm{MoO}_{x}$ core seems to be a mixed phase valence, the Mo $3 \mathrm{~d}$ oxidation states are shown by the dark and light blue curve, and sulfur signals are denoted by green. exposure to hydrazine, there is no detectable shift in the peak positions of the Mo $3 \mathrm{~d}$ binding energies for $2 \mathrm{H}-\mathrm{MoS}_{2}$ and only a slight broadening of the $S 2 p$ binding energy, but no noticeable shift. For comparison, the XPS spectra for chemically exfoliated $1 \mathrm{~T}-\mathrm{MoS}_{2}$ and $2 \mathrm{H}-\mathrm{MoS}_{2}$ sheets are shown, modified from Cummins et al. ${ }^{30}$ It is well established that the phase transition from semiconducting $2 \mathrm{H}-\mathrm{MoS}_{2}$ to metallic $1 \mathrm{~T}-\mathrm{MoS}_{2}$ has a corresponding large XPS binding energy shift of $\sim 0.9 \mathrm{eV}$ (ref. 21), which is clearly evident in the chemically exfoliated control sample, but is not observed during the hydrazine treatment; it appears that hydrazine does not induce phase transition of $\mathrm{MoS}_{2}$ from $2 \mathrm{H}$ to $1 \mathrm{~T}$ phase. This lack of phase transformation from $2 \mathrm{H}$ to $1 \mathrm{~T}$ is also corroborated using Raman spectroscopy. The Raman analysis of $\mathrm{MoS}_{2}$ is discussed in Supplementary Note 1, with the Raman spectra shown in Supplementary Fig. 6. It has been shown that the $1 \mathrm{~T}-\mathrm{MoS}_{2}$ crystal phase results in unique Raman excitations, which can distinguish the metastable phase from the stable $2 \mathrm{H}-\mathrm{MoS}_{2}$ structure $^{21,30}$; these excitations are not detected in the hydrazine-treated samples.

Electrical measurements on nanowires and 2D materials. Spectroscopic studies indicate that the oxide core is reduced, but do not reveal the effects of hydrazine on the $\mathrm{MoS}_{2}$ shell or pure $\mathrm{MoS}_{2}$ particles; therefore, in situ four-probe resistance and conductivity measurements, as well as gate-dependent measurements, are performed to elucidate the effects of hydrazine on both core-shell nanowires and CVD grown flakes. Initially, the $\mathrm{MoO}_{\mathrm{x}} / \mathrm{MoS}_{2}$ core-shell nanowire array is grown directly on a non-conducting glass substrate and mounted on a ceramic holder; two thermocouples and two copper wires (as current leads) are attached to the sample with silver epoxy to measure four point probe resistance prior and following hydrazine vapour exposure. The probe is loaded into a quartz reactor, which was placed inside a tube furnace. The experimental setup is described schematically in the Supplementary Fig. 7. Initial measurements of the resistance at atmospheric pressure and room temperature result in a value of $1.588 \mathrm{k} \Omega$. The system is evacuated to $\sim 10^{-5}$ Torr and annealed at $150^{\circ} \mathrm{C}$ to remove surface adsorbed moisture; an initial resistance of $\sim 706 \Omega$ for the as-grown $\mathrm{MoO}_{\mathrm{x}} / \mathrm{MoS}_{2}$ core-shell nanowire array is observed. To compare the effect of air and moisture on the resistivity of the core-shell nanowires, the sample is first exposed to ambient air, to a maximum pressure of 350 Torr, which results in a minimal increase in the sample resistance $(\sim 708 \Omega)$, as seen in Fig. $4 \mathrm{a}$. The system is then evacuated again and the resistance stabilized. Then, hydrazine vapours (15 Torr) are introduced to the system. Almost immediately $(<30 \mathrm{~s})$, a drop in the sample's resistance is observed, decreasing from $\sim 710$ to $\sim 495 \Omega$, which stabilizes after $\sim 30 \mathrm{~min}$, as shown in Fig. $4 \mathrm{~b}$. On evacuation of the system and, therefore, the removal of the hydrazine, the sample's resistance does not significantly increase, maintaining an average resistance of $\sim 500 \Omega$. This experimentally confirms that the hydrazine markedly lowers the sample's resistance (increases the conductivity), and thereby, improves the charge transfer characteristics during HER.

For further confirmation, conductivity measurements are performed on a core-shell nanowire back-gated device. The nanostructures are transferred onto $\mathrm{Si}^{+}+/ \mathrm{SiO}_{2}$ substrates and the electrical contacts $(\mathrm{Au})$ are defined using e-beam lithography (inset of Fig. 4c). Figure 4c shows the change in resistance of a $\mathrm{MoO}_{\mathrm{x}} / \mathrm{MoS}_{2}$ core-shell nanowire cluster, before and after hydrazine treatment. It can be clearly observed that after hydrazine treatment (red curve) the current increases sharply in comparison with the untreated device (black curve) for the 

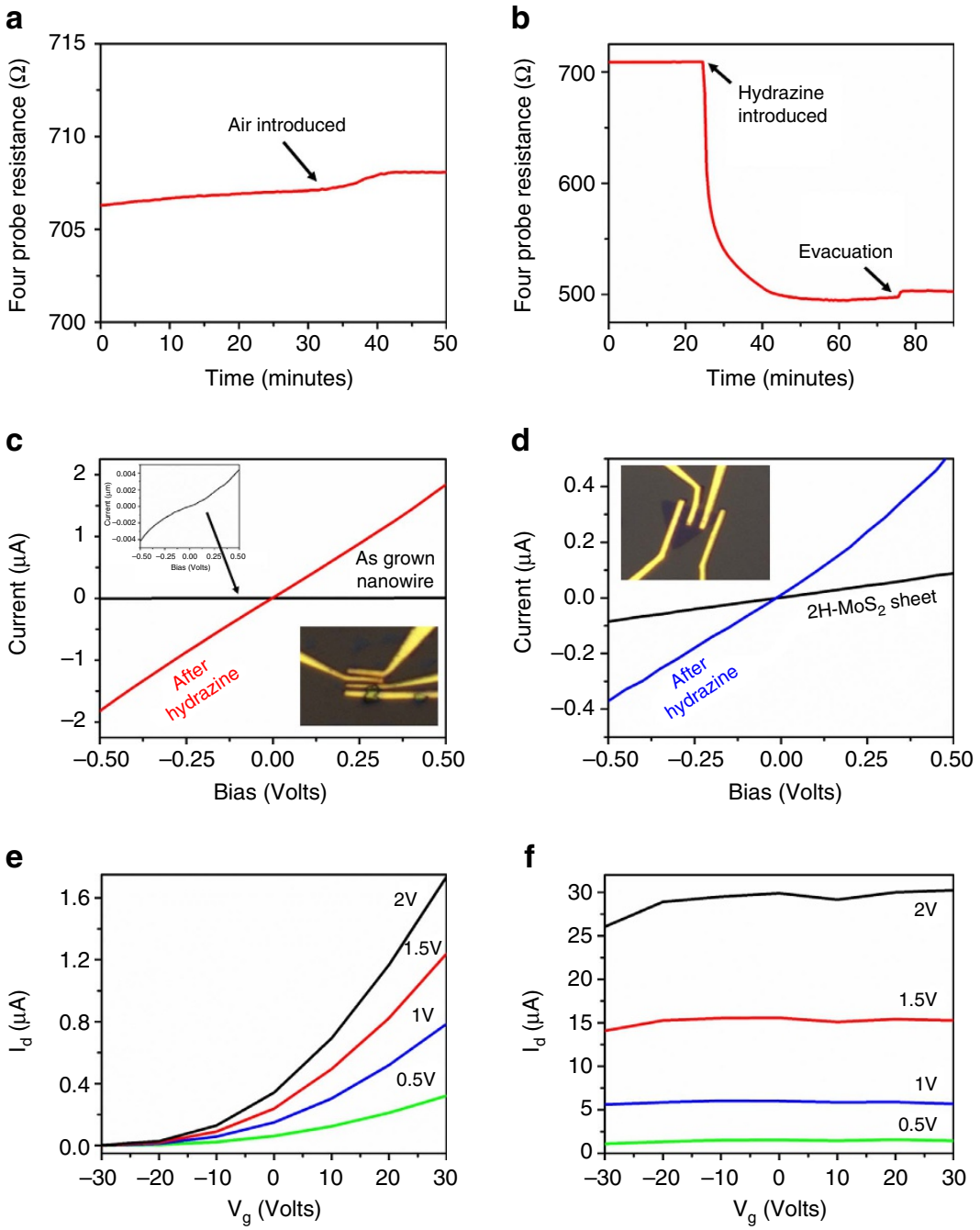

Figure 4 | Effects of hydrazine treatment on conductivity of $\mathbf{M o S}_{\mathbf{2}}$ architectures. (a) Four-probe resistance measurement of $\mathrm{MoO}_{x} / \mathrm{MoS}_{2}$ core-shell nanowire array, grown on a non-conductive glass substrate, with exposure to ambient air (shown by arrow) to $\sim 350$ Torr. (b) The effects on the four-probe resistance of the $\mathrm{MoO}_{x} / \mathrm{MoS}_{2}$ core-shell nanowire array following the introduction of a small amount ( $\sim 15$ Torr) of hydrazine $\left(\mathrm{N}_{2} \mathrm{H}_{4}\right)$ vapour, leading to an almost instantaneous, and irreversible drop in the system resistance. (c) Resistance measurement of device fabricated on a small cluster of $\mathrm{MoO}_{x} / \mathrm{MoS}_{2}$ core-shell nanowires (optical micrograph shown in inset). The resistance of the nanowires decreases from $\sim 133$ to $0.3 \mathrm{M} \Omega$ following exposure to hydrazine. (d) Resistance measurement of device fabricated on single CVD grown $2 \mathrm{H}-\mathrm{MoS}_{2}$ sheet (optical micrograph shown in inset). The resistance decreases from $\sim 5.8$ to $1.2 \mathrm{M} \Omega$ following exposure to hydrazine. (e) Drain current-gate voltage analysis of single CVD grown $2 \mathrm{H}-\mathrm{MoS}_{2}$ sheet and (f) following exposure to dilute hydrazine.

nanowires. The $\mathrm{MoO}_{\mathrm{x}} / \mathrm{MoS}_{2}$ core-shell nanowires show a resistance of $\sim 133 \mathrm{M} \Omega$ before hydrazine treatment, decreasing markedly to $\sim 0.3 \mathrm{M} \Omega$ following the hydrazine treatment.

To isolate the $\mathrm{MoS}_{2}$ system from contributions of the reduced oxide core, the resistance measurements are then performed on a single layered $\mathrm{CVD}$ grown $2 \mathrm{H}-\mathrm{MoS}_{2}$ flake ${ }^{49}$. Figure $4 \mathrm{~d}$ shows the resistance change in the single flake before and after the hydrazine treatment. The $\mathrm{MoS}_{2}$ flake shows a resistance of $\sim 5.8 \mathrm{M} \Omega$ before hydrazine treatment; following exposure to hydrazine, the resistance decreases to $\sim 1.2 \mathrm{M} \Omega$. These results directly support the hypothesis that the hydrazine treatment leads to a decrease in the resistance (or increased conductivity) of $\mathrm{MoS}_{2}$. In addition, field-effect gating experiments are performed on a single CVD-grown $2 \mathrm{H}-\mathrm{MoS}_{2}$ sheet. The effect on drain current $\left(I_{\mathrm{d}}\right)$ with changing gate bias $\left(V_{\mathrm{g}}\right)$ held at constant drain-source voltages $\left(V_{\mathrm{ds}}\right)$ on the untreated $\mathrm{MoS}_{2}$ sheet is shown in Fig. 4e. The as-grown $\mathrm{MoS}_{2}$ shows a ON/OFF ratio of $\sim 10^{3}$ (for $V_{\mathrm{ds}}=2 \mathrm{~V}$ ) and exhibits n-type behaviour, consistent with literature reports for CVD grown $\mathrm{MoS}_{2}$ (ref. 50). Following these measurements, this $\mathrm{MoS}_{2}$ sheet is treated with hydrazine, thoroughly rinsed with distilled water, and then the field effect gating is measured again (Fig. 4f). In contrast to the untreated device, there is no observable modulation with changing gate voltage and the drain current increases by an order of magnitude. This lack of modulation and increase in current shows the emergence of metallic behaviour following exposure to hydrazine, most likely due to the new states and increased carrier density at the Fermi energy. These experiments support the conclusion that hydrazine electron dopes $\mathrm{MoS}_{2}$, in pure sheets as well as the nanowire shell, improving conductivity and electrocatalytic properties.

Gate-dependent electrochemical HER measurements. The increase in the conductivity and its correlation to HER catalysis is further corroborated with back gate-dependent electrochemical HER measurements. A single layer $2 \mathrm{H}-\mathrm{MoS}_{2}$ flake is patterned with gold contacts using e-beam lithography; a schematic 

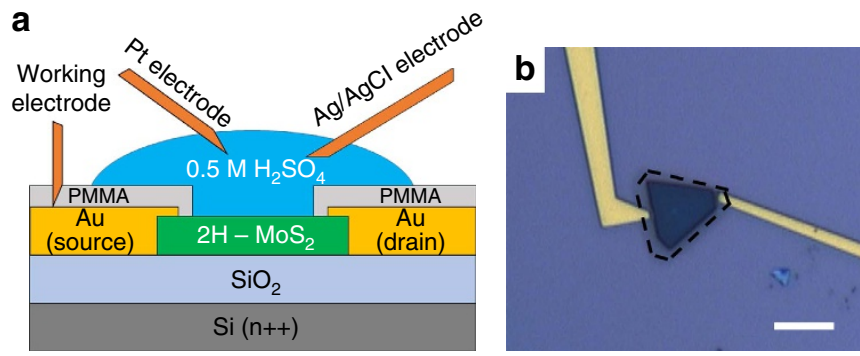

C

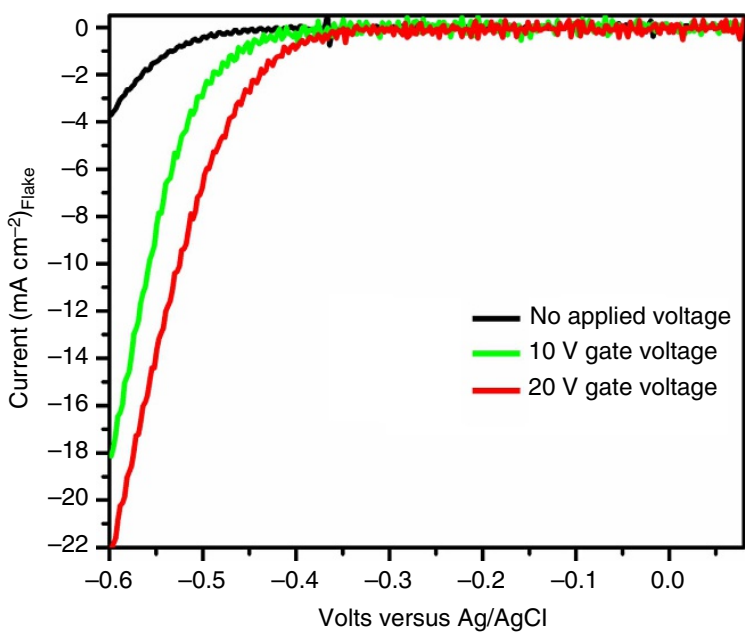

Figure 5 | Gate-Dependent HER. (a) Schematic of the gate-dependent electrochemical device, with the $\mathrm{SiO}_{2}$ layer acting as the gate. (b) Optical micrograph of gold contacts and $2 \mathrm{H}-\mathrm{MoS}_{2}$ single layer flake. The edges of the $\mathrm{MoS}_{2}$ flake masked with PMMA are outlined by the black dotted line, the exposed window can be seen as the darker region. Scale bar, $10 \mu \mathrm{m}$ (c) Linear voltammograms from the gate-dependent HER measurements on the single $\mathrm{MoS}_{2}$ flake device. The black curve is the activity of the flake with no applied voltage. The green and red curves show the improvement in electrocatalytic activity after applying a positive gate voltage of 10 and $20 \mathrm{~V}$, respectively.

representation of the experimental setup is shown in Fig. 5a. The flake and contacts are covered completely with polymethylmethacrylate (PMMA) polymer and a window $\left(\sim 140 \mu \mathrm{m}^{2}\right)$ is opened over to the surface of the flake to allow for electrocatalysis, taking special care to ensure the gold contacts are still covered by the polymer. An optical microscopic image of the device can be seen in Fig. 5b. To test the HER activity, a small drop of $0.5 \mathrm{M} \mathrm{H}_{2} \mathrm{SO}_{4}$ is placed on the flake and linear voltammograms are taken, with a thin platinum wire acting as the counter electrode and $\mathrm{AgCl}$-coated $\mathrm{Ag}$ wire acting as the pseudo reference electrode. The results of the gate-dependent HER catalysis measurements are shown in Fig. $5 \mathrm{c}$. At $0 \mathrm{~V}$ bias, there is a small, but detectable, HER obtained for the $2 \mathrm{H}-\mathrm{MoS}_{2}$ flake (black curve). A $10 \mathrm{~V}$ positive bias is applied to the back gate, inducing a negative charge at the $\mathrm{MoS}_{2}$ surface (green curve). The overpotential to drive the HER is reduced ( $\sim 500$ to $\sim 400 \mathrm{mV}$ versus the $\mathrm{Ag} / \mathrm{AgCl}$ wire) and the current density increases by over four times. When the gate voltage is increased to $20 \mathrm{~V}$, the overpotential to drive the HER continues to decrease by an additional $50-100 \mathrm{mV}$ and the current increases by five times, when compared with generated current density with no gate bias. This in situ observation of the effect of surface electron concentration on HER catalysis directly shows that increasing charge concentration at the $\mathrm{MoS}_{2}$ surface can enhance the electrocatalytic activity.

\section{Discussion}

It is essential to understand the interactions between hydrazine and $\mathrm{MoS}_{2}$, as well as which mechanism leads to increased conductivity and enhancement in electrocatalysis. Hydrazine has been shown to be an intercalating compound, ${ }^{51}$ can act as a pseudo-reducing agent in TMD systems ${ }^{52}$ and also is a strong reducing agent, which can repair oxidized sulfur sites and inhibit further oxidation of the TMD surface ${ }^{39,53}$. Finally, hydrazine has also been shown to be an effective electron dopant in graphene $^{35,36}$, carbon nanotubes ${ }^{37,38}$, and experiments suggest it can improve the conductivity in PbSe quantum dots $39,53-56$. Due to these numerous possible pathways, it is somewhat challenging to pinpoint the exact mechanism; we investigate these possible mechanisms by identifying key experiments. First, no change in the d-spacing of the $\mathrm{MoS}_{2}$ nanowire shell or $\mathrm{MoS}_{2}$ sheets is observed following exposure to hydrazine (Supplementary Fig. 8); therefore, hydrazine acting as an intercalating agent is ruled out. Second, hydrazine has been proposed as pseudo-reducing agent ${ }^{52}$ in alkaline conditions. The proposed mechanism of hydrazine forming $\mathrm{OH}^{-}$to act as a pseudo-reduction agent is outlined in Supplementary Note 2 . To test this hypothesis, $\mathrm{MoS}_{2}$ particles are treated with $0.1 \mathrm{M} \mathrm{KOH}$, but show no improvement in the electrocatalytic characteristics (Supplementary Fig. 9), therefore, the pseudo-reduction of the $\mathrm{MoS}_{2}$ surface purely by $\mathrm{OH}^{-}$groups does not adequately explain the mechanism of hydrazine interaction. Third, in the case of $\mathrm{MoO}_{\mathrm{x}} / \mathrm{MoS}_{2}$ core-shell nanowires, hydrazine can interact with the oxide core, further reducing the $\mathrm{MoO}_{\mathrm{x}}$ to make it more conductive ${ }^{48}$. Hydrazine acting as a strong reducing agent is confirmed by $\mathrm{CV}$ measurements (Supplementary Fig. 5) as well as XPS studies (Fig. 3).

Finally, electron doping of $\mathrm{MoS}_{2}$ by hydrazine should facilitate the adsorption of protons; slight broadening of the sulfur $2 p$ binding energies in the XPS spectra (Fig. 3) is consistent with this modification of the surface energies. Moreover, ultraviolet photoelectron spectroscopy analysis of the hydrazine-treated $\mathrm{MoO}_{\mathrm{x}} / \mathrm{MoS}_{2}$ core-shell nanowire system supports this mechanism, providing evidence of electron donation from hydrazine to the conduction band of the $\mathrm{MoS}_{2}$ (Supplementary Fig. 10). To characterize the chemical form of hydrazine in the $\mathrm{MoO}_{\mathrm{x}} / \mathrm{MoS}_{2}$ core-shell nanowire system, the nitrogen XPS signal $(\mathrm{N} 1 \mathrm{~s})$ is analysed, shown in Supplementary Fig. 11. Following exposure to hydrazine, a $\mathrm{N} 1 \mathrm{~s}$ signal arises at $\sim 400.3 \mathrm{eV}$, which is not observed in the as-grown sample; the nitrogen signal is in the vicinity of Mo $3 \mathrm{p}$ binding energies (analogue to Mo 3d). This nitrogen binding energy corresponds to a surface absorbed amine phase, such as $\mathrm{NH}_{3}$ or a sub-amine $\left(\mathrm{NH}, \mathrm{NH}_{2} \text { and so on }\right)^{57}$. While XPS makes it difficult to exactly identify the dissociated hydrazine $\left(\mathrm{N}_{2} \mathrm{H}_{4}\right)$ species, it is clear that amine groups have absorbed on the surface. It has been shown that ammonia, $\mathrm{NH}_{3}$, can potentially act as an n-type dopant in metal oxides. ${ }^{58,59}$ However, it is more likely that a dissociated radical of hydrazine is acting as the electron donor. Thermal decomposition studies show that $\mathrm{N}_{2} \mathrm{H}_{4}$ readily decomposes to form $2 \mathrm{NH}_{2}^{-}$(ref. 60), a reactive radical species that could contribute electrons to the $\mathrm{MoS}_{2}$ surface. Recent theoretical work by Zhang et al. ${ }^{61}$ shows that at room temperatures, hydrazine hydrate readily dissociates at a catalyst surface to form radicals, which can donate electrons to the semiconductor surface. The XPS signal of an absorbed amine group supports this theorized mechanism, where dissociated hydrazine radicals $\left(\mathrm{NH}_{2}{ }^{*}\right.$ and $\left.\mathrm{NH}_{3}\right)$ are present at the $\mathrm{MoS}_{2}$ surface and capable of donating electrons. While there are amine groups on the surface, there is no evidence that there is a chemical bonding between the nitrogen and the $\mathrm{MoS}_{2}$ shell; the amine group acts as the electron donor. To conclude, in case of core-shell nanowires, hydrazine reduces the oxide core and also 
acts as an electron dopant for the $\mathrm{MoS}_{2}$ shell; in the case of pure $\mathrm{MoS}_{2}$ sheets, the change in conductivity is entirely due to electron doping.

Finally, for commercialization and technologically viable use of TMDs for hydrogen production, thermal stability and long-term durability are required. Chemically exfoliated $1 \mathrm{~T}-\mathrm{MoS}_{2}$ sheets are sensitive to temperature as the metastable phase transformation is reversed on annealing (loss of catalytic activity) ${ }^{21,31}$. Electrocatalytic activity of hydrazine-treated nanowires before and after annealing at $150^{\circ} \mathrm{C}$ for $1 \mathrm{~h}$ under argon are shown in Fig. 6a. There is no significant change in HER onset potential or current density, which demonstrates that the effect of the hydrazine treatment is not merely due to physisorption. The electrochemical durability at room temperature of the hydrazinetreated nanowires is also investigated, shown in Fig. 6b. The initial current density at $0.35 \mathrm{~V}$ versus RHE is $\sim 24 \mathrm{~mA} \mathrm{~cm}^{-2}$ following the hydrazine treatment, which is set as $100 \%$. After 10 scans, the current density at $0.35 \mathrm{~V}$ actually increases, which has been seen in other reports ${ }^{29}$, but slowly decreases to $\sim 60 \%$ of its initial activity, stabilizing after around 400 cycles to an average of $\sim 13 \mathrm{~mA} \mathrm{~cm}^{-2}$. This degradation may be due, in part, to decomposition of the oxide core, since the $\mathrm{MoS}_{2}$ shell is thinner than in other reports ${ }^{29}$.

In conclusion, exposure of $\mathrm{MoO}_{\mathrm{x}} / \mathrm{MoS}_{2}$ core-shell nanowires to an aqueous hydrazine solution leads to a marked improvement in
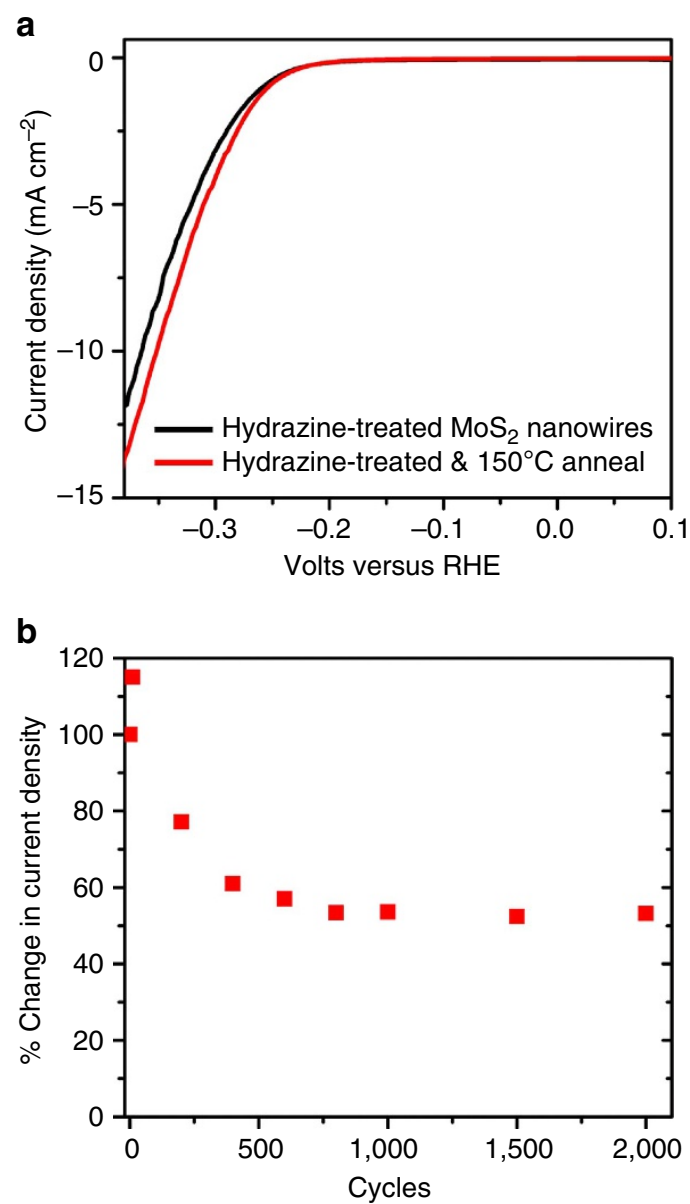

Figure 6 | Stability studies of hydrazine-treated $\mathrm{MoO}_{\mathbf{x}} / \mathrm{MoS}_{\mathbf{2}}$ core-shell nanowire. (a) Linear voltammetry for $\mathrm{MoO}_{x} / \mathrm{MoS}_{2}$ core-shell nanowires treated with Hydrazine (red curve), then annealed at $150^{\circ} \mathrm{C}$ for $1 \mathrm{~h}$ (red dashed line). (b) Stability of hydrazine-treated $\mathrm{MoO}_{x} / \mathrm{MoS}_{2}$ core-shell nanowires over 2,000 cycles. Current densities are normalized to $\sim 24 \mathrm{~mA} \mathrm{~cm}^{-2}$ as $100 \%$. electrocatalytic activity. We observe a $100 \mathrm{mV}$ improvement in the HER onset potential (from approximately $-200 \mathrm{mV}$ to approximately $-100 \mathrm{mV}$ versus RHE) and also an exponential increase in generated current density (from 2 to $22 \mathrm{~mA} \mathrm{~cm}^{-2}$ at $-0.35 \mathrm{~V}$ versus RHE). Furthermore, the TOF for the core-shell nanowires increases five-fold following the hydrazine treatment, from 0.04 to $0.2 \mathrm{~s}^{-1}$, due to the synergistic reduction of the oxide core and the electron doping of the $\mathrm{MoS}_{2}$ shell. In the case of $\mathrm{MoS}_{2}$ bulk powder, the TOF increases by nearly twofold, from 0.03 to $0.05 \mathrm{~s}^{-1}$, since electron doping is the only contributing factor. Surface characterization studies reveal that the change in catalytic properties does not result from a phase transformation, but is due to enhanced conductivity. The increased conductivity, as result of hydrazine treatment, is shown in $\mathrm{MoO}_{\mathrm{x}} / \mathrm{MoS}_{2}$ core-shell nanowires, $2 \mathrm{H}-\mathrm{MoS}_{2}$ particles, and single layer sheets, by utilizing field effect gating experiments, conductivity, and spectroscopic techniques. Hydrazine is shown to act as an electron dopant; dissociated amine radicals donate electrons to the $\mathrm{MoS}_{2}$ surface, facilitating electrocatalysis. The reported hydrazine modifications can be performed in ambient conditions and on the order of minutes, when compared to conventional techniques. This is one of the first known investigations into the effect of hydrazine exposure in 2D layered chalcogenides for electrocatalysis application. Understanding the effects of hydrazine on TMDs in catalysis can lead to a fundamental breakthrough in the areas of electrochemistry and material science.

\begin{abstract}
Methods
Electrochemical testing measurements. To examine the electronic properties of the nanowires, $1 \%$ by volume hydrazine $\left(\mathrm{N}_{2} \mathrm{H}_{4}\right)$ and water solution $(20 \mu \mathrm{l})$ was dropped directly on the nanowire array and allowed to dry in air $(\sim 10 \mathrm{~min})$. Electrodes were prepared by gently dispersing the hydrazine-treated nanowire array in distilled water, then transferred to $3 \mathrm{~mm}$ diameter glassy carbon tip electrodes $\left(\sim 70 \mu \mathrm{g} \mathrm{cm}^{-2}\right)$. A thin layer of $5 \%$ Nafion $\left(\sim 2.7 \mu \mathrm{l} \mathrm{cm}^{-2}\right)$ was further applied on the electrodes to prevent delamination of the active material into solution, but still allowing for proton transport. The electrochemical analysis was performed by cyclic voltammetry in $0.5 \mathrm{M} \mathrm{H}_{2} \mathrm{SO}_{4}$ solution $(\mathrm{pH}=0)$ using a graphite rod as counter electrode and $\mathrm{Ag} / \mathrm{AgCl}$ as a reference electrode $(+0.210 \mathrm{~V}$ versus RHE). Nitrogen was bubbled vigorously through the electrolyte to remove any oxygen from solution. The sample was cycled multiple times to remove surface contamination and ensure steady state conditions.

For electrochemical measurements of bulk $\mathrm{MoS}_{2}$ powder, the powder was dispersed by sonication in distilled water $\left(100 \mathrm{mg} \mathrm{MoS}_{2}\right.$ per $\left.10 \mathrm{ml} \mathrm{H}_{2} \mathrm{O}\right)$ and drop-cast onto glassy carbon electrodes $\left(\sim 1 \mathrm{mg} \mathrm{cm}^{-2}\right)$. For the hydrazine treatment, the dried $\mathrm{MoS}_{2}$ dispersion on glassy carbon was drop-cast with $1 \%$ hydrazine solution and allowed to dry, then coated with Nafion, following the exact methods as with the core-shell nanowires.
\end{abstract}

Gate device fabrication and conductivity measurements. For fabrication of the $\mathrm{MoS}_{2}$ sheet devices, $\mathrm{MoS}_{2}$ monolayer sheets were grown using standard CVD procedure $^{49}$ and transferred onto $300 \mathrm{~nm} \mathrm{SiO} / \mathrm{Si}^{+}+$substrates by the PMMA assisted transfer method. PMMA layers were then washed by acetone under $50^{\circ} \mathrm{C}$ followed by IPA rinse. In the case of the $\mathrm{MoO}_{\mathrm{x}} / \mathrm{MoS}_{2}$ core-shell nanowire device, the nanowires are first dispersed by sonication in water, then directly drop-casted onto the $300 \mathrm{~nm} \mathrm{SiO} 2 / \mathrm{Si}^{+}+$substrates. PMMA was spin-coated at 3,000 r.p.m. for $60 \mathrm{~s}$, followed by a soft bake at $180^{\circ} \mathrm{C}$. The electrode patterns were defined by using standard e-beam lithography method (5/40 nm Ti/Au contacts). This was followed by a lift-off process to achieve the final device configuration. Initial conductivity measurements and gate-dependent measurements were performed on these devices in vacuum. To test the effect of hydrazine, another e-beam lithography step was performed to selectively expose a region within the device channel to isolate the contacts. Hydrazine treatment was performed by placing a $1 \%$ dilute hydrazine solution for $5 \mathrm{~min}$ to a few hours. The devices are then thoroughly rinsed with distilled water and electrical measurements performed again in vacuum.

Characterization instrumentation. FEI Tecnai F20 TEM was used for high-resolution TEM. SEM imaging utilizes a FEI Quanta FEG 400 Scanning Electron Microscope. XPS analysis is performed using a Physical Electronics 5600ci XPS system with an $\mathrm{Al} \mathrm{K} \alpha$ radiation source. All XPS spectra are calibrated by the position of the $\mathrm{C} 1 \mathrm{~s}$ peak. The carbon signal used for calibration results from surface absorbed hydrocarbons, which have a characteristic peak location of $284.5 \mathrm{eV}$. The Raman spectroscopic analysis of the nanowire arrays is performed 
using a Renishaw Invia Micro Raman system with a $633 \mathrm{~nm}$ HeNe laser. Raman system is calibrated using single crystal $\mathrm{Si}$ wafer, with characteristic peak at $520.0 \mathrm{~cm}^{-1}$.

Data availability. The data that support the findings of this study are available on request from the corresponding author G.G.

\section{References}

1. James, B. D., Baum, G. N., Perez, J. \& Baum, K. N. Technoeconomic Analysis of Photoelectrochemical (PEC) Hydrogen Production. Report No. GS-10F-009J, published on U.S. DOE EERE website.www1.eere.doe.gov/hydrogenandfuelcells/ pdfs/pec_technoeconomic_analysis.pdf (US Department of Energy, 2009).

2. Ashcroft, A. T., Cheetham, A. K., Green, M. L. H. \& Vernon, P. D. F. Partial oxidation of methane to synthesis gas-using carbon-dioxide. Nature 352, 225-226 (1991).

3. Cortright, R. D., Davda, R. R. \& Dumesic, J. A. Hydrogen from catalytic reforming of biomass-derived hydrocarbons in liquid water. Nature 418, 964-967 (2002).

4. Rostrup-Nielsen, J. R., Sehested, J. \& Norskov, J. K. in Advances in Catalysis Vol. 47 (eds Gates, B. C. \& Knozinger, H.) 65-139 (2002).

5. Joo, S. H. et al. Ordered nanoporous arrays of carbon supporting high dispersions of platinum nanoparticles. Nature 412, 169-172 (2001).

6. Si, Y. C. \& Samulski, E. T. Exfoliated graphene separated by platinum nanoparticles. Chem. Mater. 20, 6792-6797 (2008).

7. Sheng, W. C., Gasteiger, H. A. \& Shao-Horn, Y. Hydrogen oxidation and evolution reaction kinetics on platinum: acid vs alkaline electrolytes. J. Electrochem. Soc. 157, B1529-B1536 (2010).

8. Khaselev, O. \& Turner, J. A. A monolithic photovoltaic-photoelectrochemical device for hydrogen production via water splitting. Science 280, 425-427 (1998).

9. Chhowalla, M. et al. The chemistry of two-dimensional layered transition metal dichalcogenide nanosheets. Nat. Chem. 5, 263-275 (2013).

10. Benck, J. D. et al. Catalyzing the hydrogen evolution reaction (HER) with molybdenum sulfide nanomaterials. ACS Catal. 4, 3957-3971 (2014).

11. Chianelli, R. R. et al. The reactivity of $\mathrm{MoS}_{2}$ single-crystal edge planes. J. Catal. 92, 56-63 (1985).

12. Kibsgaard, J., Chen, Z. B., Reinecke, B. N. \& Jaramillo, T. F. Engineering the surface structure of $\mathrm{MoS}_{2}$ to preferentially expose active edge sites for electrocatalysis. Nat. Mater. 11, 963-969 (2012).

13. Lauritsen, J. V. et al. Size-dependent structure of MoS2 nanocrystals. Nat. Nanotechnol. 2, 53-58 (2007).

14. Kong, D. S. et al. Synthesis of $\mathrm{MoS}_{2}$ and $\mathrm{MoSe}_{2}$ films with vertically aligned layers. Nano Lett. 13, 1341-1347 (2013).

15. Wu, Z. Z. et al. $\mathrm{MoS}_{2}$ nanosheets: a designed structure with high active site density for the hydrogen evolution reaction. ACS Catal. 3, 2101-2107 (2013).

16. Tsai, C., Abild-Pedersen, F. \& Norskov, J. K. Tuning the $\mathrm{MoS}_{2}$ edge-site activity for hydrogen evolution via support interactions. Nano Lett. 14, 1381-1387 (2014).

17. Chen, Z. B., Forman, A. J. \& Jaramillo, T. F. Bridging the gap between bulk and nanostructured photoelectrodes: the impact of surface states on the electrocatalytic and photoelectrochemical properties of $\mathrm{MoS}_{2}$. J. Phys. Chem. C 117, 9713-9722 (2013).

18. Ho, W. K. et al. Preparation and photocatalytic behavior of $\mathrm{MoS}_{2}$ and $\mathrm{WS}_{2}$ nanocluster sensitized $\mathrm{TiO}_{2}$. Langmuir 20, 5865-5869 (2004).

19. Hinnemann, B. et al. Biornimetic hydrogen evolution: $\mathrm{MoS}_{2}$ nanoparticles as catalyst for hydrogen evolution. J. Am. Chem. Soc. 127, 5308-5309 (2005).

20. Li, Y. et al. $\mathrm{MoS}_{2}$ nanoparticles grown on graphene: an advanced catalyst for the hydrogen evolution reaction. J. Am. Chem. Soc. 133, 7296-7299 (2011).

21. Eda, G. et al. Photoluminescence from chemically exfoliated $\mathrm{MoS}_{2}$. Nano Lett. 11, 5111-5116 (2011).

22. Py, M. A. \& Haering, R. R. Structural destabilization induced by lithium iintercalation in $\mathrm{MoS}_{2}$ and related-compounds. Can. J. Phys. 61, 76-84 (1983).

23. Joensen, P., Frindt, R. F. \& Morrison, S. R. Single-layer $\mathrm{MoS}_{2}$. Mater. Res. Bull. 21, 457-461 (1986).

24. Matte, H. et al. $\mathrm{MoS}_{2}$ and $\mathrm{WS}_{2}$ analogues of graphene. Angew. Chem. Int. Ed. 49, 4059-4062 (2010).

25. Coleman, J. N. et al. Two-dimensional nanosheets produced by liquid exfoliation of layered materials. Science 331, 568-571 (2011).

26. Voiry, D. et al. Enhanced catalytic activity in strained chemically exfoliated $\mathrm{WS}_{2}$ nanosheets for hydrogen evolution. Nat. Mater. 12, 850-855 (2013).

27. Gao, M. R. et al. An efficient molybdenum disulfide/ cobalt diselenide hydrid catalyst for electrochemical hydrogen generation. Nat. Commun. 6, 5982 (2015).

28. Wang, H. T. et al. Electrochemical tuning of vertically aligned $\mathrm{MoS}_{2}$ nanofilms and its application in improving hydrogen evolution reaction. Proc. Natl Acad. Sci. USA 110, 19701-19706 (2013).
29. Chen, Z. et al. Core-shell $\mathrm{MoO}_{3}-\mathrm{MoS}_{2}$ nanowires for hydrogen evolution: a functional design for electrocatalytic materials. Nano Lett. 11, 4168-4175 (2011).

30. Cummins, D. R. et al. Catalytic activity in lithium-treated core-shell $\mathrm{MoO}_{\mathrm{x}} / \mathrm{MoS}_{2}$ nanowires. J. Phys. Chem. C 119, 22908-22914 (2015).

31. Voiry, D. et al. Conducting $\mathrm{MoS}_{2}$ nanosheets as catalysts for hydrogen evolution reaction. Nano Lett. 13, 6222-6227 (2013).

32. Lukowski, M. A. et al. Enhanced hydrogen evolution catalysis from chemically exfoliated metallic $\mathrm{MoS}_{2}$ nanosheets. J. Am. Chem. Soc. 135, 10274-10277 (2013).

33. Wang, H. T. et al. Electrochemical tuning of $\mathrm{MoS}_{2}$ nanoparticles on threedimensional substrate for efficient hydrogen evolution. ACS Nano 8, 4940-4947 (2014).

34. Eda, G., Fanchini, G. \& Chhowalla, M. Large-area ultrathin films of reduced graphene oxide as a transparent and flexible electronic material. Nat. Nanotechnol. 3, 270-274 (2008).

35. Lee, I.-Y. et al. Hydrazine-based n-type doping process to modulate Dirac point of graphene and its application to complementary inverter. Org. Electron. 14, 1586-1590 (2013).

36. Feng, T. et al. Electron-doping of graphene-based devices by hydrazine. J. Appl. Phys. 116, 224511-1-224511-6 (2014).

37. Mistry, K. S. et al. n-type transparent conducting films of small molecule and polymer amine doped single-walled carbon nanotubes. ACS Nano 5, 3714-3723 (2011).

38. Klinke, C., Chen, J., Afzali, A. \& Avouris, P. Charge transfer induced polarity switching in carbon nanotube transistors. Nano Lett. 5, 555-558 (2005).

39. Talapin, D. V. \& Murray, C. B. PbSe nanocrystal solids for $n$ - and p-channel thin film field-effect transistors. Science 310, 86-89 (2005).

40. Lee, I. et al. Non-degenerate n-type doping by hydrazine treatment in metal work function engineered $\mathrm{WSe}_{2}$ field-effect transistor. Nanotechnology 26, 455203 (2015).

41. Cummins, D. R. Synthesis of Molybdenum Oxide Nanowires and Their Facile Conversion to Molybdenum Sulfide. Master of Engineering thesis, Univ. Louisville (2009).

42. Pentland, N., Bockris, J. O. \& Sheldon, E. Hydrogen evolution reaction on copper, gold, molybdenum, palladium, rhodium, and iron. J. Electrochem. Soc. 104, 182-194 (1957).

43. Conway, B. E. \& Tilak, B. V. Interfacial processes involving electrocatalytic evolution and oxidation of $\mathrm{H}_{2}$, and the role of chemisorbed $\mathrm{H}$. Electrochim Acta 47, 3571-3594 (2002).

44. Bonde, J. et al. Hydrogen evolution on nano-particulate transition metal sulfides. Faraday Discuss. 140, 219-231 (2008).

45. Merki, D. \& Hu, X. Recent developments of molybdenum and tungsten sulfides as hydrogen evolution catalysts. Energy Environ. Sci. 4, 3878-3888 (2011).

46. Jaramillo, T. F. et al. Identification of active edge sites for electrochemical H-2 evolution from $\mathrm{MoS}_{2}$ nanocatalysts. Science 317, 100-102 (2007).

47. Pourbaix, M. Atlas of Electrochemical Equilibria in Aqueous Solutions 2nd edn (NACE International, 1974).

48. Hu, B., Mai, L. Q., Chen, W. \& Yang, F. From $\mathrm{MoO}_{3}$ nanobelts to $\mathrm{MoO}_{2}$ nanorods: structure transformation and electrical transport. ACS Nano 3, 478-482 (2009).

49. Bilgin, I. et al. Chemical vapor deposition synthesized atomically thin molybdenum disulfide with optoelectronic-grade crystalline quality. ACS Nano 9, 8822-8832 (2015).

50. Kappera, R. et al. Phase-engineered low-resistance contacts for ultrathin $\mathrm{MoS}_{2}$ transistors. Nat. Mater. 13, 1128-1134 (2014).

51. Subba Rao, G. V. \& Shafer, M. W. Intercalation in Layered Transition Metal Dichalcogenides 99-199 (D. Reidel Publishing Company, 1979).

52. Schollhorn, R., Sick, E. \& Lerf, A. Reversible topotacti redox reactions of layered dichalcogenides. Mater. Res. Bull. 10, 1005-1012 (1975).

53. Steckel, J. S., Coe-Sullivan, S., Bulovic, V. \& Bawendi, M. G. $1.3 \mu \mathrm{m}$ to $1.55 \mu \mathrm{m}$ tunable electroluminescence from $\mathrm{PbSe}$ quantum dots embedded within an organic device. Adv. Mater. 15, 1862-1866 (2003).

54. Williams, K. J. et al. Strong electronic coupling in two-dimensional assemblies of colloidal PbSe quantum dots. ACS Nano 3, 1532-1538 (2009).

55. Law, M. et al. Structural, optical, and electrical properties of PbSe nanocrystal solids treated thermally or with simple amines. J. Am. Chem. Soc. 130, 5974-5985 (2008).

56. Talapin, D. V. et al. Alignment, electronic properties, doping, and on-chip growth of colloidal PbSe nanowires. J. Phys. Chem. C 111, 13244-13249 (2007)

57. Bischoff, J. L., Lutz, F., Bolmont, D. \& Kubler, L. Use of multilayer techniques for xps indentification of various nitrogen environments in the $\mathrm{Si} / \mathrm{NH}_{3}$ system. Surf. Sci. 251, 170-174 (1991).

58. Bang, J. et al. Molecular doping of $\mathrm{ZnO}$ by ammonia: a possible shallow acceptor. J. Mater. Chem. C 3, 339-344 (2015).

59. Huang, J. Y. et al. Growth of $\mathrm{N}$-doped p-type $\mathrm{ZnO}$ films using ammonia as dopant source gas. J. Mater. Sci. Lett. 22, 249-251 (2002).

60. Szwarc, M. The dissociation energy of the N-N bond in hydrazine. Proc. $R$ Soc. Lond. Ser. A 198, 267-284 (1949). 
61. Zhang, C. et al. Transfer hydrogenation of nitroarenes with hydrazine at near-room temperature catalysed by a $\mathrm{MoO}_{2}$ catalyst. Green Chem. 18, 2435-2442 (2016).

\section{Acknowledgements}

This work was funded primarily by Los Alamos Directed Research Grant. This work was performed, in part, at the Center for Integrated Nanotechnologies, an Office of Science User Facility operated for the U.S. Department of Energy (DOE) Office of Science. Los Alamos National Laboratory, an affirmative action equal opportunity employer, is operated by Los Alamos National Security, LLC, for the National Nuclear Security Administration of the US Department of Energy under contract DE-AC52-06NA25396. The authors would also like to acknowledge the Conn Center for Renewable Energy Research at the University of Louisville for facilities and access to characterization equipment. Development of samples and characterization was supported partially by DOE EPSCoR (DE-FG02-07ER46375) and by a graduate fellowship funded by NASA Kentucky under NASA award No: NNX10AL96H. We thank Dan Kelly and Joseph Dumont at Los Alamos National Laboratory for assistance with XPS analysis. We thank National Science Foundation NSF EPSCoR Grant 1355438 for supporting this work.

\section{Author contributions}

G.G., A.D.M. and M.K.S. designed the experiments and organization of the manuscript. D.R.C. developed the synthesis of the core/shell nanowires, applied the dilute hydrazine treatments, electrochemical measurements, and characterization (SEM, Raman and XPS). D.R.C. and G.G. co-wrote the manuscript. U.M. along with D.R.C. performed the electrochemical analysis. A.S. and G.S. designed and conducted in situ conductivity experiments. R.K. developed the gate-dependent HER experimental setup and assisted with measurements. A.M.-G. synthesized $\mathrm{MoS}_{2}$ core-shell nanowires. R.K.S. performed XPS on core-shell nanowires and assisted with interpretation. J.J. conducted TEM analysis and assisted with XPS and UPS interpretation. R.K.G. performed electrochemical tests on $\mathrm{MoS}_{2}$ bulk powders. J.Z. and J.L. fabricated nanowire and CVD flake field effect devices and performed conductivity measurements. M.C. provided valuable input and understanding of $2 \mathrm{D}$ materials and overall organization of the manuscript.

\section{Additional information}

Supplementary Information accompanies this paper at http://www.nature.com/ naturecommunications

Competing financial interests: The authors declare no competing financial interests.

Reprints and permission information is available online at http://npg.nature.com/ reprintsandpermissions/

How to cite this article: Cummins, D. R. et al. Efficient hydrogen evolution in transition metal dichalcogenides via a simple one-step hydrazine reaction. Nat. Commun. 7:11857 doi: 10.1038/ncomms11857 (2016)

(c) (i) This work is licensed under a Creative Commons Attribution 4.0 International License. The images or other third party material in this article are included in the article's Creative Commons license, unless indicated otherwise in the credit line; if the material is not included under the Creative Commons license, users will need to obtain permission from the license holder to reproduce the material. To view a copy of this license, visit http://creativecommons.org/licenses/by/4.0/ 